Article

\title{
Relationship between Nutrition and Alcohol Consumption with Blood Pressure: The ESTEBAN Survey
}

\author{
Alexandre Vallée ${ }^{1, *(\mathbb{D}}$, Amélie Gabet ${ }^{2}$, Valérie Deschamps ${ }^{2}$, Jacques Blacher ${ }^{1}$ and Valérie Olié ${ }^{2}$ \\ 1 Paris-Descartes University, Diagnosis and Therapeutic Center, Hypertension and Cardiovascular Prevention \\ Unit, Hôtel-Dieu Hospital, AP-HP, 75004 Paris, France; jacques.blacher@aphp.fr \\ 2 Santé Publique France, The French Public Health Agency, 94410 Saint-Maurice, France; \\ Amelie.GABET@santepubliquefrance.fr (A.G.); valerie.deschamps@univ-paris13.fr (V.D.); \\ Valerie.OLIE@santepubliquefrance.fr (V.O.) \\ * Correspondence: alexandre.g.vallee@gmail.com; Tel.: +33-142348587
}

Received: 3 June 2019; Accepted: 24 June 2019; Published: 25 June 2019

check for updates

\begin{abstract}
Background: Dietary interventions are recommended for the prevention of hypertension. The aim of this study was to evaluate and quantify the relationship between alcohol consumption and the DASH (Dietary Approaches to Stop Hypertension) score with blood pressure (BP) stratified by gender. Methods: Cross-sectional analyses were performed using data from 2105 adults from the ESTEBAN survey, a representative sample of the French population. Pearson correlation analyses were used to assess the correlation between the DASH score and alcohol with BP. Regressions were adjusted by age, treatment, socio-economic level, tobacco, exercise, Body mass index (BMI), and cardiovascular risk factors and diseases. Results: The DASH score was negatively correlated with systolic (SBP) and diastolic BP (DBP) $(p<0.0001)$. Alcohol was positively associated with increased $\mathrm{BP}$ only in men. The worst quintile of the DASH score was associated with an $1.8 \mathrm{mmHg}$ increase in SBP and an $0.6 \mathrm{mmHg}$ increase in SBP compared to the greatest quintile in men and with a $1.5 \mathrm{mmHg}$ increase in SBP and an $0.4 \mathrm{mmHg}$ increase in SBP in women. Male participants in the worst quintile of alcohol consumption showed an increase of $3.0 \mathrm{mmHg}$ in SBP and $0.8 \mathrm{mmHg}$ in DBP compared to those in the greatest quintile. Conclusion: A high DASH score and a reduction in alcohol consumption could be effective nutritional strategies for the prevention of hypertension.
\end{abstract}

Keywords: DASH; blood pressure; diet; hypertension; alcohol

\section{Introduction}

The prevalence of noncommunicable diseases has spread alarmingly around the world in both sexes and among all age subgroups [1]. Hypertension, one of the most important risk factors of noncommunicable diseases, is a major global public health problem affecting more than $30 \%$ of adults worldwide [2].

The major treatments prescribed for hypertension are dietary interventions, exercise, and medication [3]. Current guidelines for the prevention and treatment of hypertension emphasize lifestyle modifications which should enhance antihypertensive drug efficacy [3]. Dietary Approaches to Stop Hypertension (DASH) is a widely used dietary intervention for hypertension and is recommended by the American Heart Association. Previous studies have shown that the DASH diet lowers BP in those who normally have high blood pressure (BP) and has been recommended for the prevention and treatment of hypertension [4-7]. Moreover, when augmented by exercise and weight loss, the DASH diet can considerably benefit patients with high BP, not only by reducing BP but also by leading to favorable modification of disease risk biomarkers $[8,9]$. The DASH diet is rich in vegetables, fruits, 
low-fat dairy products, and legumes, and low in animal proteins. However, while many studies have investigated associations between diet and the incidence of hypertension, few studies have investigated the changes in BP and DASH diet indicators [4,5]. Indeed, several studies have shown a relationship between DASH and hypertension $[6,10,11]$. However, although there is strong and consistent evidence that adopting a DASH diet leads to a reduction in BP in hypertensive adults, the relationship between DASH and BP in the general population (hypertensive or not) is less reported $[5,6,12,13]$. Hypertension is a disease characterized by a persistent increase in BP. From this evidence, the control of arterial BP is important not only in hypertensive subjects but also in the general population [3]. Hypertension is largely a by-product of modern lifestyle determinants, including alcohol consumption. Recent guidelines recommend limiting daily alcohol intake to two or fewer drinks for men and 1 or fewer drinks for women [3]. Several studies have confirmed the association between heavy drinking and the development of hypertension [14]. However, this association remains unclear. The association may also depend on gender, which could be related to differential patterns [15].

Therefore, the aim of this study was to evaluate and quantify the relationships between alcohol consumption and the DASH score and its different components with parameters of blood pressure stratified by gender among a representative population of French adults.

\section{Methods}

\subsection{Study Design}

The ESTEBAN survey is a cross-sectional study that was conducted on a representative population of French adults. The protocol of the Esteban survey has been published previously [16]. One of the objectives of the Esteban survey was to describe food consumption, physical activity, sedentariness, and nutritional status and to estimate the prevalence of certain chronic diseases and vascular risk factors. The design of the Esteban survey was probabilistic at three degrees. In the first stage, a stratified sample of primary units was drawn. At the second level, in each primary unit, households were randomly selected by telephone sampling. At the third level, only one individual was randomly selected from the eligible household members. Stratification was carried out according to two variables: the region (8 geographical areas) and the degree of urbanization (5 strata: rural, $<20,000$ inhabitants, $20,000-100,000$ inhabitants, $>100,000$ inhabitants, Paris). Data comprised dietary intake descriptions, clinical and biochemical marker measurements, physical activity, and complementary items assessed by questionnaires. The study was registered at the French National Agency for Medicines and Health Products Safety (No. 2012-A00456-34) and was approved by the Advisory Committee for Protection of Persons in Biomedical Research.

\subsection{Study Population}

A total of 3021 adults was included between April 2014 and March 2016. After exclusion of participants, valid BP and adiposity-related measurements were available for 2105 participants who were included in the analyses (Figure 1).

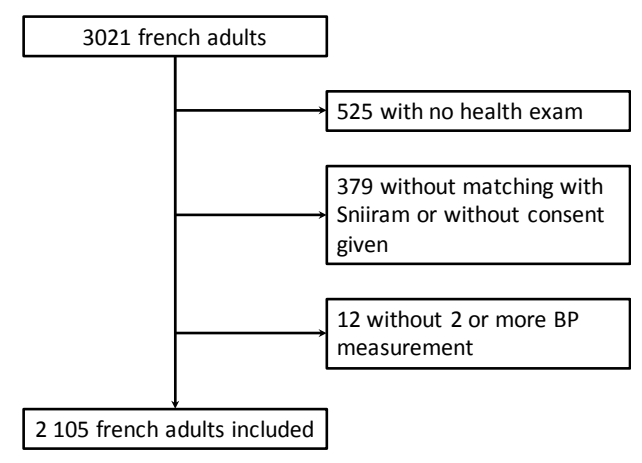

Figure 1. Flow chart, Esteban survey 2014-2016. 


\subsection{Dietary Intake Assessment}

Dietary data were collected using three $24 \mathrm{~h}$ recalls, one of which was on the weekend, randomly distributed within a 2 week period. Participants were not previously informed of the call day to limit changes in eating habits for the survey. Specific questionnaires were used to investigate salt intake to describe the use of salt in cooking and salt added with a salt shaker during meals. Additional data were collected concerning the usual consumption of episodically consumed foods. In this paper, diet intake is reported based on the $24 \mathrm{~h}$ recalls ( $\mathrm{g} /$ day). Consumption of alcoholic beverages was assessed using a combination of an annual propensity questionnaire and $24 \mathrm{~h}$ recalls (g/day).

The DASH-style diet, as previously developed by Fung et al. [17], includes 8 dietary components which should be increased (fruits, vegetables, legumes, low-fat dairy, whole grains) or minimized (salt, sweetened beverages, red and processed meats). For each component, participants' scores (ranging from 1 to 5) were based on sex-specific quintiles. The final DASH score, ranging from 8 to 40 , was then obtained by adding the scores for each component. A high DASH score indicates a high intake of dietary fruits, vegetables, etc., and a low intake of salt, sweetened beverages, and meats. Quintiles of DASH scores were constructed to estimate the effect of the DASH classification on BP. Q1 was designated as the best quintile of DASH score and Q5 as the worst.

\subsection{Blood Pressure and Other Anthropometric Measure Definitions}

Body mass index (BMI) and blood pressure measurements were taken during the clinical examination based on standardized operational procedures. Weight and height were measured (respectively by a stadiometer fixed to a wall and Tanita scale with digital read-out), and BMI was calculated as body weight $(\mathrm{kg})$ divided by the square of height $(\mathrm{m})$.

Blood pressure was measured with an Omron 705-IT blood pressure monitor on the right arm using a cuff adapted to the circumference of the arm. Measurements were taken at $30 \mathrm{~min}$ from the blood test and after 5 min of rest, without change of position. Three measurements were made, 1 min apart. The systolic BP (SBP) and diastolic BP (DBP) for each person were taken the average of the last two measurements. People for whom at least two BP measurements were not completed were excluded from the analysis. Information on antihypertensive treatments were obtained by matching the individual data of the subjects included in the study with the data from the Sniiram (National inter-scheme health insurance information system). The names of the treatments and the reimbursement dates in the year preceding the health examination were collected.

\subsection{Disease Definitions}

Hypertension was defined as a systolic BP of $\geq 140 \mathrm{~mm} \mathrm{Hg}$ and/or a mean diastolic BP of $\geq 90 \mathrm{~mm}$ $\mathrm{Hg}$ and/or antihypertensive treatment [3]. Hypercholesterolemia was considered if participants reported treating the condition or if the total cholesterol level was $\geq 6.61 \mathrm{mmol} / \mathrm{L}(255 \mathrm{mg} / \mathrm{dL})$. Chronic kidney disease was defined as known proteinuria or decreased renal function (creatinine clearance $<60 \mathrm{~mL} / \mathrm{min}$ calculated by the Cockroft-Gault equation) for more than 3 months [18], or a chronic kidney disease diagnosed by biopsy or renal ultrasound and confirmed by a nephrologist. Participants were considered diabetic if they reported that they had been declared diabetic by a physician (or professional health worker) in the past or if they were currently using anti-diabetic treatment (oral agents or injections), or if they were declared diabetic by the physician in the health screening examination, or if their fasting blood glucose was $\geq 7 \mathrm{mmol} / \mathrm{L}$. They were classified as non-diabetic otherwise.

\subsection{Socioeconomic Status}

Sociodemographic and economic data were collected by a questionnaire administered face-to-face during the first home visit. Duration of work was categorized in two classes: fixed-term contract and indefinite contract. Education level was determined according to the International Standard Classification of Education (ISCED) [19] and was then classified into three levels: High school 
diploma or less ( $\leq 13$ years of education), undergraduate degree (14-16 years of education), and postgraduate degree ( $\geq 17$ years of education). From the baseline questionnaires, we used the following sociodemographic variables: marital status (i.e., single (single/separated/widowed or divorced, and couple: marital or non-marital) and household income (i.e., <1600; 1600-2500; 2500-4600; >4600 euros per month).

\subsection{Statistical Analysis}

For the participants who underwent a health examination, the probability of inclusion was calculated to consider the complex survey design. In addition, to consider a potential participation bias, calibration by age, education diploma, and the presence of at least one child in the household, according to French national census data and the period of collection, was performed separately for each gender. Calibration was carried out using the SAS macro program CALMAR (CALibration on MARgins), and census data came from the National Institute for Statistics and Economic Studies (Insee). Descriptive analyses were performed for the entire population and for each gender using counts and percentages or means \pm standard deviations (SDs) for quantitative variables, or frequencies and percentages for categorical variables for the entire population and for each gender. For categorical variables, we used the Pearson's Chi-square or Fisher's exact tests, where applicable. Continuous quantitative variables were analyzed using the student (independent) $t$-test and Mann-Whitney test when a normal or abnormal distribution was assumed, respectively. BP parameters were SBP and DBP. DASH components were fruits, vegetables, low-fat dairy, milk, legumes, salt, sweetened beverages, and red and processed meats. Relationships were determined using linear regression models to assess the associations between covariables of interest and BP parameters. To investigate the determinants of BP, we used a multiple linear regression for each gender for SBP and DBP. Model-evaluated DASH scores and alcohol consumption were adjusted by age, education level, income level, term of contract, BMI, physical activity, hypercholesterolemia, diabetes, chronic kidney disease, previous cardiovascular (CV) disease, and antihypertensive therapy. First, we used a linear regression to evaluate the association between the DASH score and alcohol consumption with BP parameters (as continuous variables) and second, in same models, we included all the nutrient parameters of the DASH score and alcohol consumption to evaluate the independent determinants of BP parameters. Then, quintiles of the DASH score and alcohol consumption were constructed to evaluate their effects on BP gain or loss. The results were reported for each model as the square partial correlation coefficient, $r^{2}$, which was used to describe the contribution of each parameter to BP variability. All tests were 2-sided; $p<0.05$ was considered statistically significant. Statistical analyses were done using SAS software (version 9.4; SAS Institute, Carry, NC, USA).

\section{Results}

The characteristics of the 2105 included participants ( 945 men and 1160 women) stratified by gender are displayed in Table 1 . The mean age of the study population $( \pm \mathrm{SD})$ was $47.2 \pm 14.6$ years. The mean BMI $( \pm S D)$ was $25.9 \pm 5.1 \mathrm{~kg} / \mathrm{m}^{2}$. The mean SBP $( \pm \mathrm{SD})$ was $127 \pm 19 \mathrm{mmHg}$. Smokers represented $23.9 \%$ of the participants. A total of $32.3 \%$ of our study population had a postgraduate degree. Among the 2105 participants, the prevalence of hypertension was 31.3\%, 38.1\% for men and $25.0 \%$ for women. Antihypertensive medication was taken by $48.9 \%$ of the hypertensive participants.

Hypertensive participants displayed higher BMI values $\left(28.2 \pm 5.7 \mathrm{~kg} / \mathrm{m}^{2}\right)$ than those were normotensive $\left(24.9 \pm 4.4 \mathrm{~kg} / \mathrm{m}^{2}, p<0.0001\right)$, had higher daily alcohol consumption $(10.2 \pm 11.3 \mathrm{vs}$. $7.2 \mathrm{~g} \pm 9.2, p<0.0001)$, higher frequency of diabetes $(12.4 \%$ vs. $3.7 \%, p=0.004)$, higher frequency of hypercholesterolemia $(32.8 \%$ vs. $15.9 \%, p<0.0001)$ and lower DASH scores $(23 \pm 4$ vs. $24 \pm 4$, $p=0.0002$ ).

In the multiple linear regression models, DASH score was independently and negatively associated with the two blood pressure parameters (SBP, DBP) in both genders $(p<0.0001)$ (Table 2$)$. 
Table 1. Characteristics of the study population, Esteban survey 2014-2016.

\begin{tabular}{|c|c|c|c|c|}
\hline Characteristics & All & Men & Women & $p$ Value * \\
\hline$N$ & 2105 & 945 & 1160 & \\
\hline Age (years) & $47.2(14.6)$ & $47.7(14.3)$ & $46.7(14.8)$ & 0.61 \\
\hline Familial status & & & & $<0.0001$ \\
\hline Couple & $68.4 \%$ & $72.7 \%$ & $64.5 \%$ & \\
\hline Single & $31.6 \%$ & $27.3 \%$ & $35.5 \%$ & \\
\hline Education level & & & & $<0.0001$ \\
\hline$<$ High school diploma & $32.3 \%$ & $32.0 \%$ & $32.0 \%$ & \\
\hline Undergraduate degree & $56.5 \%$ & $56.1 \%$ & $56.9 \%$ & \\
\hline Postgraduate degree & $11.2 \%$ & $11.3 \%$ & $11.1 \%$ & \\
\hline Income & & & & $<0.0001$ \\
\hline Very high $(>4200)$ & $10.5 \%$ & $12.6 \%$ & $8.4 \%$ & \\
\hline High & $40.6 \%$ & $39.9 \%$ & $41.2 \%$ & \\
\hline Medium & $27.2 \%$ & $28.2 \%$ & $26.2 \%$ & \\
\hline Low $(<1600)$ & $21.8 \%$ & $19.3 \%$ & $24.2 \%$ & \\
\hline Contract & & & & 0.0003 \\
\hline Indefinite contract & $84.9 \%$ & $89.4 \%$ & $80.9 \%$ & \\
\hline Fixed-term contract & $15.1 \%$ & $10.6 \%$ & $19.1 \%$ & \\
\hline BMI $\left(\mathrm{kg} / \mathrm{m}^{2}\right)$ & $25.9(5.1)$ & $26.1(4.4)$ & $25.7(5.2)$ & $<0.0001$ \\
\hline Alcohol (g/day) & $8.2(9.9)$ & $12.4(11.9)$ & $4.3(5.3)$ & $<0.0001$ \\
\hline DASH score & $23(4)$ & $23(4)$ & $24(4)$ & $<0.0001$ \\
\hline Vegetables (g/day) & $191.2(71.6)$ & 189.5 (73.2) & $192.71(70.2)$ & 0.44 \\
\hline Legumes (g/day) & $12.7(6.1)$ & $16.2(6.6)$ & $9.5(3.7)$ & $<0.0001$ \\
\hline Red and processed meats ( $\mathrm{g} /$ day) & $126.1(36.9)$ & $148.5(33.3)$ & $105.4(26.6)$ & $<0.0001$ \\
\hline Dairy products (g/day) & $75.1(106.9)$ & $82.4(120.3$ & $68.3(92.7)$ & 0.0009 \\
\hline Wholegrains (g/day) & $2.84(3.87)$ & $3.0(3.9)$ & $2.6(3.8)$ & 0.001 \\
\hline Juice and fruits $(\mathrm{g} /$ day $)$ & $220.4(129.9)$ & $224.7(135.6)$ & $216.5(124.7)$ & 0.09 \\
\hline Sweetened beverages (g/day) & $76.3(152.9)$ & $87.6(158.5)$ & $65.9(146.9)$ & $<0.0001$ \\
\hline Salt (g/day) & $8.2(2.7)$ & $9.3(2.8)$ & $7.2(2.2)$ & $<0.0001$ \\
\hline Current smoker & $23.9 \%$ & $27.1 \%$ & $20.9 \%$ & $<0.0001$ \\
\hline \multicolumn{5}{|l|}{ Physical activity } \\
\hline High & $10.6 \%$ & $15.6 \%$ & $6.1 \%$ & $<0.0001$ \\
\hline Moderate & $51.3 \%$ & $56.2 \%$ & $46.9 \%$ & \\
\hline Low & $38.1 \%$ & $28.2 \%$ & $47.0 \%$ & \\
\hline Diabetes & $6.5 \%$ & $7.7 \%$ & $5.4 \%$ & $<0.0001$ \\
\hline Hypercholesterolemia & $21.2 \%$ & $22.3 \%$ & $20.1 \%$ & 0.31 \\
\hline Chronic kidney disease & $1.8 \%$ & $1.3 \%$ & $2.3 \%$ & 0.04 \\
\hline Previous CV disease & $4.5 \%$ & $5.8 \%$ & $3.2 \%$ & 0.0002 \\
\hline Systolic BP & $127(19)$ & $132(18)$ & $122(18)$ & $<0.0001$ \\
\hline Diastolic BP & $77(11)$ & 79 (11) & $75(10)$ & $<0.0001$ \\
\hline $\begin{array}{c}\text { Pulse pressure } \\
\text { Mean BP }\end{array}$ & $50(13)$ & $53(13)$ & $47(12)$ & \\
\hline Hypertension & $31.3 \%$ & $38.1 \%$ & $25.0 \%$ & $<0.0001$ \\
\hline Antihypertensive drugs ${ }^{* *}$ & $48.9 \%$ & $47.5 \%$ & $51.1 \%$ & $<0.0001$ \\
\hline
\end{tabular}

Values are means \pm standard deviation, or numbers and \% in parenthesis. BP: blood pressure, BMI: body mass index, CV: cardiovascular, DASH: Dietary Approaches to Stop Hypertension. * $p$ value, difference between men and women. ** among hypertensives.

Table 2. Multivariate linear regression of the DASH score and alcohol consumption for blood parameters.

\begin{tabular}{ccccccccccc}
\hline & \multicolumn{3}{c}{ Men } & & & \multicolumn{3}{c}{ Women } \\
\hline & & $\begin{array}{c}\boldsymbol{r}^{2} \text { value } \\
\mathbf{( \% )}\end{array}$ & Estimate & Std & $p$ value & $\begin{array}{c}\boldsymbol{r}^{2} \text { value } \\
\mathbf{( \% )}\end{array}$ & Estimate & Std & $p$ Value \\
\hline $\mathrm{SBP}^{*}$ & DASH & 0.14 & -0.13 & $(0.07)$ & $<0.0001$ & 1.13 & -0.61 & $(0.17)$ & $<0.0001$ \\
$\mathrm{DBP}^{*}$ & score & 0.13 & -0.10 & $(0.05)$ & $<0.0001$ & 1.12 & -0.27 & $(0.10)$ & $<0.0001$ \\
\hline $\mathrm{SBP}^{* *}$ & Alcohol & 0.83 & 0.15 & $(0.03)$ & 0.007 & - & 0.05 & $(0.05)$ & 0.14 \\
$\mathrm{DBP}^{* *}$ & consumption & 0.77 & 0.11 & $(0.02)$ & 0.009 & - & 0.01 & $(0.01)$ & 0.16 \\
\hline
\end{tabular}

* Model-evaluated DASH score with BP parameters were adjusted by age, education level, income level, term of contract, alcohol, tobacco use, physical activity, BMI, hypercholesterolemia, diabetes, chronic kidney disease, antihypertensive therapy, and previous CV disease. ${ }^{* *}$ Model-evaluated alcohol consumption with BP parameters were adjusted by age, education level, income level, term of contract, DASH score, tobacco use, physical activity, BMI, hypercholesterolemia, diabetes, chronic kidney disease, antihypertensive therapy, and previous CV disease. DBP: diastolic blood pressure, SBP: systolic blood pressure. 
In men, multiple linear regression models of the decomposed components of the DASH score, for SBP: legumes $(p=0.01)$ and whole grains $(p=0.007)$ were independently and negatively associated with SBP whereas meats $(p<0.001)$ and sugary beverages $(p=0.003)$ were positively associated with SBP (Table 3).

Table 3. Multivariate linear regression including the composed factors of DASH score and alcohol for blood parameters.

\begin{tabular}{|c|c|c|c|c|c|c|c|c|c|}
\hline & \multirow[b]{2}{*}{ Parameters } & \multicolumn{3}{|c|}{ Men } & \multicolumn{5}{|c|}{ Women } \\
\hline & & $r^{2}$ value & Est. & Std & $p$ Value & $r^{2}$ value & Est. & Std & $p$ Value \\
\hline \multirow{7}{*}{$\begin{array}{c}\text { Systolic } \\
\text { blood } \\
\text { pressure }\end{array}$} & Vegetables & - & -0.01 & $(0.01)$ & 0.44 & - & -0.005 & $(0.01)$ & 0.56 \\
\hline & Red and processed meats & 0.1 & 0.12 & $(0.03)$ & $<0.0001$ & 0.1 & 0.15 & $(0.03)$ & $<0.0001$ \\
\hline & Dairy products & - & -0.001 & $(0.008)$ & 0.15 & - & -0.005 & $(0.008)$ & 0.35 \\
\hline & Wholegrains & 0.4 & -0.59 & $(0.21)$ & 0.007 & - & -0.39 & $(0.21)$ & 0.06 \\
\hline & Salt & - & 0.03 & $(0.36)$ & 0.92 & 0.1 & 1.63 & $(0.43)$ & 0.0002 \\
\hline & Alcohol consumption & 0.8 & 0.15 & $(0.2)$ & 0.001 & - & 0.03 & $(0.06)$ & 0.18 \\
\hline & Parameters & $r^{2}$ value & Est. & Std & $p$ Value & $r^{2}$ value & Est. & Std & $p$ Value \\
\hline \multirow{5}{*}{$\begin{array}{c}\text { Diastolic } \\
\text { blood } \\
\text { pressure }\end{array}$} & Vegetables & - & -0.001 & $(0.009)$ & 0.57 & - & -0.0001 & $(0.008)$ & 0.67 \\
\hline & Juice and fruits & - & -0.001 & $(0.004)$ & 0.72 & - & -0.003 & $(0.005)$ & 0.54 \\
\hline & Sweetened beverages & 0.9 & 0.01 & $(0.004)$ & 0.03 & 0.4 & 0.01 & $(0.004)$ & 0.03 \\
\hline & Salt & - & 0.68 & $(0.21)$ & 0.75 & 0.1 & 0.99 & $(0.26)$ & 0.0002 \\
\hline & Alcohol consumption & 0.8 & 0.09 & $(0.05)$ & 0.002 & - & 0.03 & $(0.08)$ & 0.16 \\
\hline
\end{tabular}

Model-evaluated nutrients and alcohol parameters were adjusted by age, education level, income level, term of contract, tobacco use, physical activity, BMI, hypercholesterolemia, diabetes, chronic kidney disease, antihypertensive therapy, and previous CV disease.

Likewise, for men, the consumption of legumes and wholegrains was negatively and independently associated with DBP, while the consumption of meats and sugary beverages was positively and independently associated with DBP.

In women, the multiple linear regression models of the decomposed components of the DASH score for SBP showed that legumes $(p=0.0001)$ were independently and negatively associated with SBP, whereas meats $(p<0.001)$, sugary beverages $(p=0.003)$, and salt $(p=0.0002)$ were positively associated with SBP.

Likewise, for women, legumes were negatively and independently associated with DBP, while meats, sugary beverages, and salt were positively and independently associated with DBP.

Male participants with DASH scores in the worst quintile (Q5) had an average SBP of $128.8 \mathrm{mmHg}$ and a DBP of $77.7 \mathrm{mmHg}$ compared to male participants with DASH scores in the highest quintile (Q1), who had an average SBP of $127.0 \mathrm{mmHg}$ and a DBP of $77.1 \mathrm{mmHg}$ (in other words, an increase of $1.8 \mathrm{mmHg}$ in SBP and $0.6 \mathrm{mmHg}$ in DBP) (Figure 2, Table 4). Female participants with DASH scores in the worst quintile (Q5) had an average SBP of $126.9 \mathrm{mmHg}$ and a DBP of $77.0 \mathrm{mmHg}$ compared to male participants with DASH scores in the highest quintile (Q1), who had an average SBP of $125.4 \mathrm{mmHg}$ and a DBP of $76.6 \mathrm{mmHg}$ (in other words, an increase of $1.5 \mathrm{mmHg}$ in SBP and $0.4 \mathrm{mmHg}$ in DBP) (Figure 3, Table 4).

In the multiple linear regression models, alcohol consumption was independently and positively associated with increased SBP and DBP values in men (respectively, $p=0.007$ and $p=0.009$ ) but not in women. Male participants with the lowest quintile of alcohol consumption had an average SBP of $128.6 \mathrm{mmHg}$ and a DBP of $77.6 \mathrm{mmHg}$ compared to male participants with the highest quintile of alcohol consumption, who had an average SBP of $125.6 \mathrm{mmHg}$ and a DBP of $76.8 \mathrm{mmHg}$ (in other words, an increase of $3.0 \mathrm{mmHg}$ in SBP and $0.8 \mathrm{mmHg}$ in DBP) (Figure 2, Table 4). 

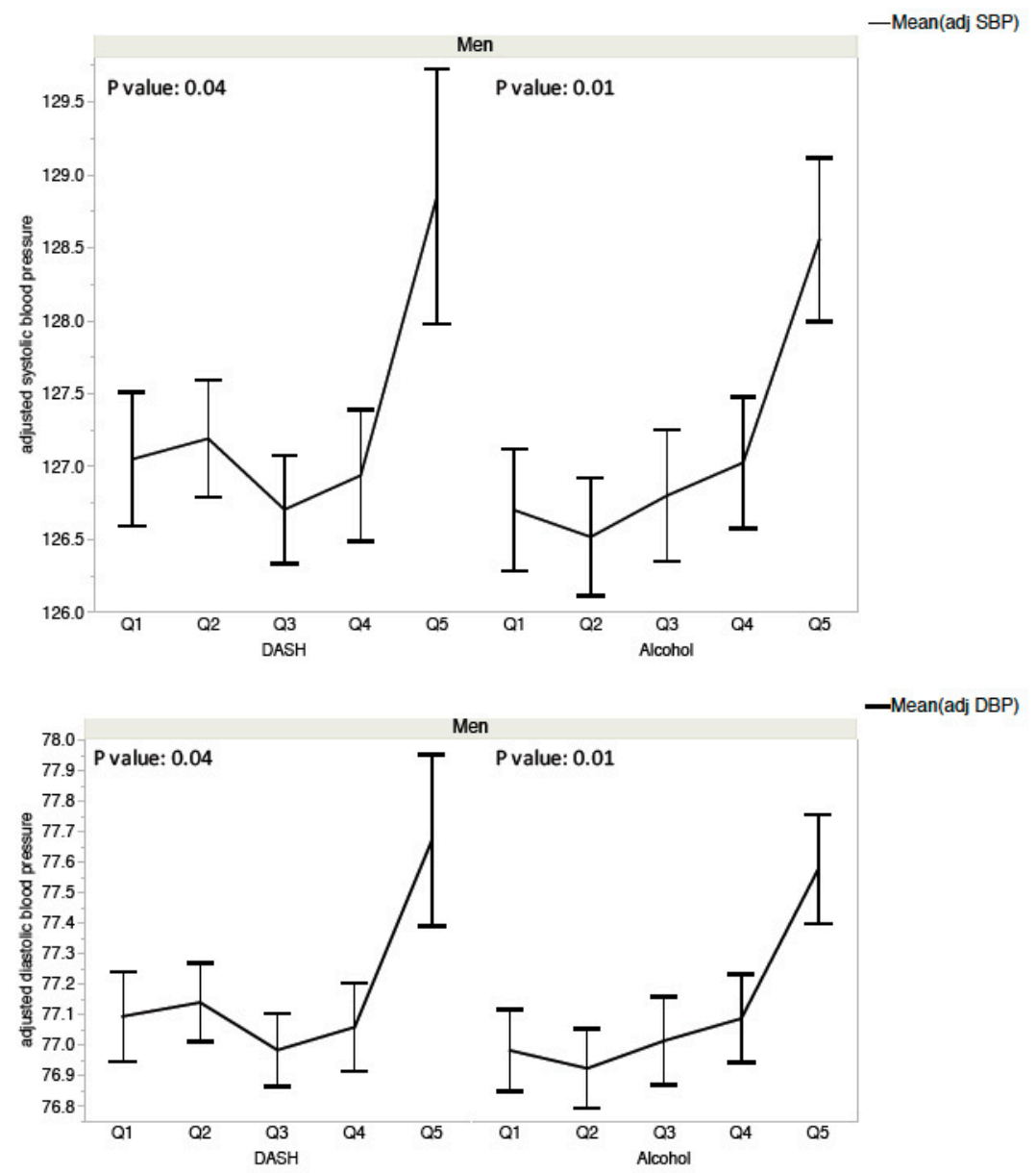

Figure 2. Blood pressure and DASH score quintiles and alcohol consumption in men from the Esteban survey 2014-2016. Q1: better quintile of DASH scores and alcohol consumption (lowest consumption).

Table 4. Adjusted BP according to quintiles of DASH scores and alcohol consumption in men and women. Q5: worst quintile of DASH scores and alcohol consumption (high) Q1: best quintile of DASH scores and alcohol consumption (lowest).

\begin{tabular}{|c|c|c|c|c|c|c|c|}
\hline DASH & $\begin{array}{l}\text { MEN } \\
\text { Score }\end{array}$ & $\begin{array}{c}\text { Q5 } \\
17(2)\end{array}$ & $\begin{array}{c}\text { Q4 } \\
21(0.7)\end{array}$ & $\begin{array}{c}\text { Q3 } \\
23(.78)\end{array}$ & $\begin{array}{c}\text { Q2 } \\
25(0.7)\end{array}$ & $\begin{array}{c}\text { Q1 } \\
28(2)\end{array}$ & $p$ value \\
\hline & SBP & $128.8(7.4)$ & $126.9(5.7)$ & $126.7(5.8)$ & $127.1(5.9)$ & $127.0(6.3)$ & 0.04 \\
\hline & DBP & $77.7(2.4)$ & $77.1(1.8)$ & $76.9(1.8)$ & $77.1(1.9)$ & $77.1(2.0)$ & 0.04 \\
\hline & $\begin{array}{c}\text { WOMEN } \\
\text { score }\end{array}$ & $\begin{array}{c}\text { Q5 } \\
18(2)\end{array}$ & $\begin{array}{c}\mathrm{Q} 4 \\
22(0.9)\end{array}$ & $\begin{array}{c}\text { Q3 } \\
24(0.8)\end{array}$ & $\begin{array}{c}\text { Q2 } \\
27(0.8)\end{array}$ & $\begin{array}{c}\text { Q1 } \\
30(2)\end{array}$ & $p$ value \\
\hline & SBP & $126.9(5.6)$ & $126.5(5.3)$ & $126.1(5.0)$ & $125.9(4.9)$ & 125.4 (3.9) & 0.01 \\
\hline & DBP & $77.0(1.8)$ & $76.9(1.7)$ & $76.8(1.6)$ & 76.7 (1.5) & $76.6(1.2)$ & 0.02 \\
\hline \multirow[t]{6}{*}{ Alcohol } & $\begin{array}{l}\text { MEN } \\
\text { g/day }\end{array}$ & $\begin{array}{c}\text { Q5 } \\
31.5(8.0)\end{array}$ & $\begin{array}{c}\mathrm{Q} 4 \\
17.2(2.7)\end{array}$ & $\begin{array}{c}\text { Q3 } \\
8.7(1.8)\end{array}$ & $\begin{array}{c}\text { Q2 } \\
3.9(1.1)\end{array}$ & $\begin{array}{c}\mathrm{Q1} \\
1.3(0.9)\end{array}$ & $p$ value \\
\hline & SBP & $128.6(7.3)$ & $127.0(5.9)$ & $126.7(5.9)$ & $126.6(5.3)$ & $125.6(5.5)$ & 0.01 \\
\hline & DBP & $77.6(2.4)$ & 77.1 (1.9) & $77.1(1.7)$ & $76.9(1.8)$ & $76.8(1.5)$ & 0.01 \\
\hline & $\begin{array}{c}\text { WOMEN } \\
\text { g/day }\end{array}$ & $\begin{array}{c}\text { Q5 } \\
14.3(5.3)\end{array}$ & $\begin{array}{c}\mathrm{Q} 4 \\
5.2(1.2)\end{array}$ & $\begin{array}{c}\text { Q3 } \\
2.5(0.4)\end{array}$ & $\begin{array}{c}\mathrm{Q} 2 \\
1.2(0.2)\end{array}$ & $\begin{array}{c}\mathrm{Q} 1 \\
0.5(0.4)\end{array}$ & $p$ value \\
\hline & SBP & $126.5(5.0)$ & $126.1(5.0)$ & $125.9(4.5)$ & $126.0(5.2)$ & $125.9(4.8)$ & 0.74 \\
\hline & DBP & $76.9(1.5)$ & $76.8(1.6)$ & $76.7(1.5)$ & $76.7(1.6)$ & $76.7(1.6)$ & 0.73 \\
\hline
\end{tabular}




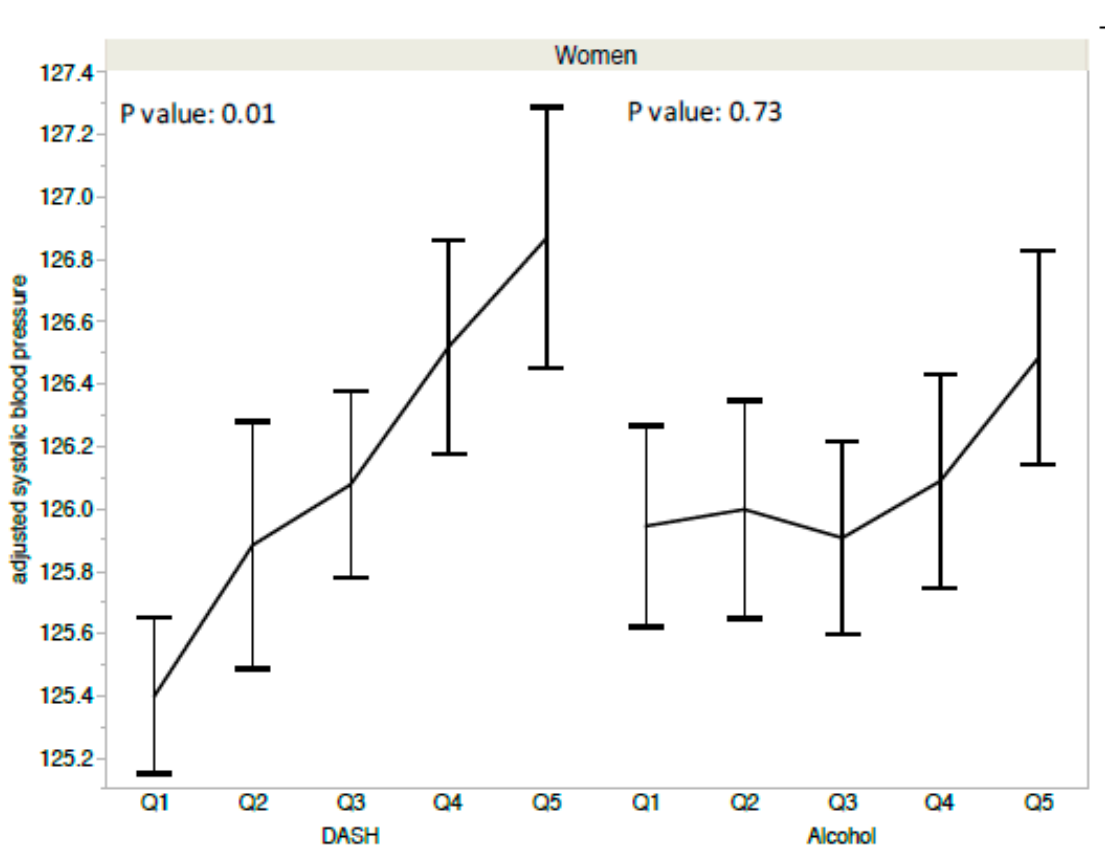

-Mean(adj SBP)

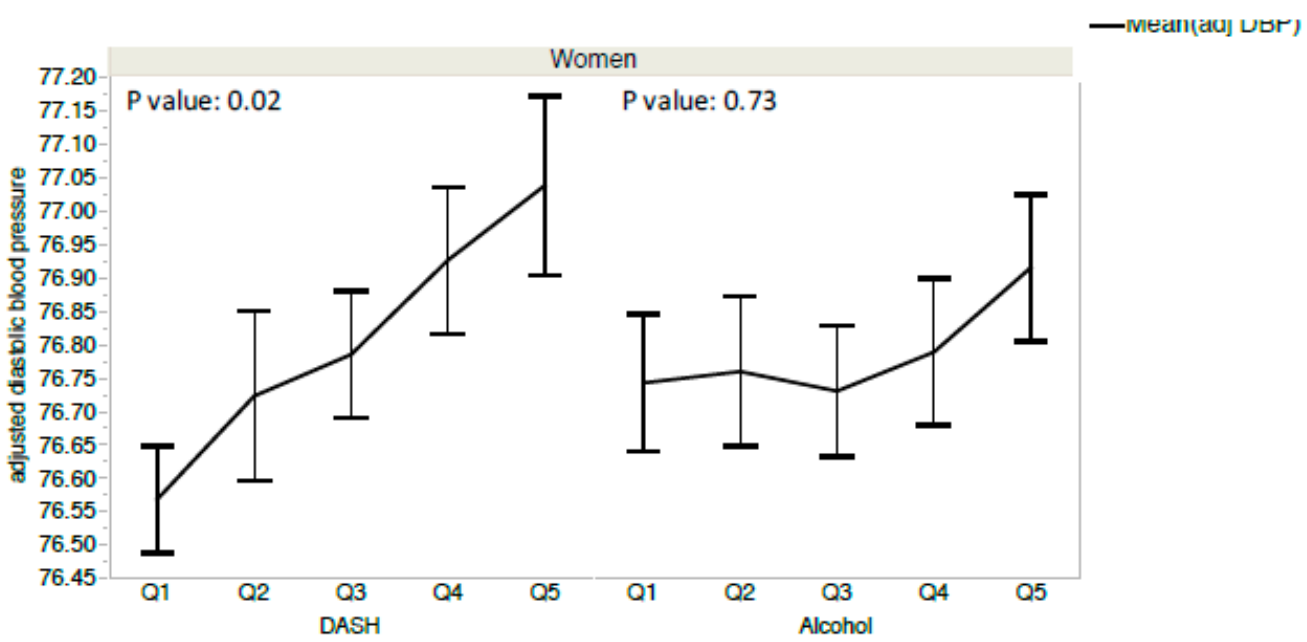

Figure 3. Blood pressure and quintiles of DASH score and alcohol consumption in women from the Esteban survey 2014-2016. Q1: better quintile of DASH scores and alcohol consumption (lowest consumption).

\section{Discussion}

The main result of our study was that, in both genders, the DASH score was independently and negatively associated with BP variation, whereas alcohol consumption was only correlated with BP variation in men. Moreover, some differences appeared based on gender in the relationships between $\mathrm{BP}$ and the components of DASH score.

\subsection{DASH Score and Blood Pressure}

Two recent meta-analyses showed that the DASH diet significantly reduces BP. Saneei et al. showed that the DASH diet significantly reduces SBP by $6.74 \mathrm{mmHg}$ and DBP by $3.54 \mathrm{mmHg}$ [13], and Ndanuko et al. showed that the DASH diet significantly reduces SBP by $4.90 \mathrm{mmHg}$ and DBP by $2.63 \mathrm{mmHg}$ [20]. Some observational studies have reported a negative association between the DASH diet and blood pressure $[12,21,22]$ which is consistent with our results. In a recent study among French volunteers (excluding hypertensive subjects undergoing vasoactive treatment), the DASH pattern was as follows: in females, the DASH diet was inversely associated with SBP, whereas for 
males, this association was not significant [6]. In contrast, in a cross-sectional study conducted in the framework of the Irish Mitchelstown Cohort Study, a significant inverse relationship emerged between adherence to the DASH diet and SBP in both genders [21]. Moreover, in the SU.VI.MAX cohort (individuals reporting antihypertensive treatment excluded), the DASH score was correlated with lower SBP and DBP at baseline and a lower BP increase after a follow-up period of 5 years [22]. In a European cohort (SUN (Seguimiento Universidad deNavarra) prospective cohort), it was observed that higher adherence to the DASH diet was correlated with a lower risk of developing hypertension $(p=0.02)$ [11]. On the contrary, a European cohort found no dose-response correlation between diet score and hypertension. This could be explained by the fact that the DASH scores in that study were derived from only three food components (vegetables, fruits, and milk products) [23].

\subsection{Components of the DASH Score and BP}

Animal Products

Recent studies have reported that the intake of animal products (red and processed meats) is correlated with an increased risk of hypertension [5,24]. The noxious content of these foods results from the process of cooking, which produces advanced glycoxidation end-products (AGEs) and heterocyclic amines (HCAs) that increase oxidative stress and inflammation, counteracting the potential beneficial effect of protein intake from these foods. The longitudinal Chicago Western Electric Study observed that men who consumed 0.5 to 1.5 cups/day vs. less than 0.5 cups/day of vegetables presented a $2 \mathrm{mmHg}$ lower rise in SBP over seven years $(p<0.05)$, whereas the consumption of beef, veal, lamb, and poultry was associated with a greater SBP/DBP increase $(p<0.05)$ [25]. Recently, an association between elevated fasting plasma trimethylamide N-oxide (TMAO) and an increased risk for main adverse CV events was identified [26]. TMAO is a metabolite of phosphatidylcholine and L-carnitine, which are both abundant in red meat. TMAO has been found to affect the hemodynamic effect of chronically infused angiotensin II [27], a pivotal hormone in circulatory system homeostasis. By affecting protein folding, TMAO affects the affinity of receptors as well as the activity of enzymes and hormones involved in the control of circulatory system homeostasis [26].

\subsection{Gender Differences between Components of the DASH Score and BP}

\subsubsection{Salt Intake}

Our study also identified a gender difference in the association between BP and nutritional factors. A few observational studies have reported this discrepancy but with inconsistent results $[6,22,28]$. We found that BP was associated with salt intake in women but not with men, when adjusted for all parameters. Several hypotheses can explain this finding. Data from a controlled dietary trial suggested that low dietary sodium intake may be more effective in reducing BP among women due to their higher salt sensitivity compared with men [29]. Dietary questionnaires only covered salt intake from foods. Total consumption was estimated by adding a constant for cooking meals and eating, which could have reduced the inter-individual variation and thus could made the potential correlation more difficult to identify. Another explanation is that the known relationship between BP and salt in the general population has been overstated and is more complex than once believed $[28,30]$.

\subsubsection{Legumes and Wholegrains}

The consumption of legumes is known to be correlated with lower BP levels [28,30,31]. This association could be explained by the high potassium and fiber contents of these vegetables, which have been found to reduce BP levels [32-34]. Our results are consistent with those in the literature in that we found a negative and independent correlation between BP parameters and the intake of legumes in both genders. 
The negative correlation between wholegrain consumption and BP can be explained by the ability of wholegrains to increase insulin sensitivity [31]. According to the results of our study, the association between dietary fiber and lower BP has been reported in several studies in men but not in women [5,35]. Moreover, a synergistic effect of fibers, i.e., wholegrains, with potassium and magnesium could improve mineral absorption in the gastrointestinal system $[36,37]$.

There is significant evidence for a clear association between the microbiome and BP [38]. Indeed, hypertensive patients have different gut microbiome contents than individuals with normal BP [39]. Fecal transplant from hypertensive patients to gnotobiotic (germ free) mice led to an increase in $\mathrm{BP}$ (around $15 \mathrm{mmHg}$ ), gut metabolites resulting from the microbial fermentation of prebiotics are associated with lower BP values [39], and changes in the gut microbiome support the existence of a gut-cardio-renal axis and a gut-central nervous system axis $[39,40]$. The microbiome can be modulated by the intake of fiber, leading to a lower BP [40]. Moreover, this mechanism involves the production of short-chain fatty acids as by-products of the fermentation of fiber by intestinal bacteria [41].

\subsubsection{Sugar-Sweetened Beverages}

Sugar-sweetened beverages (SSB) are the main source of added sugar in the diet. Many studies have presented a positive correlation between increased BP and consumption of SSB [42]. They reported, in general, that an intake of $>12 \mathrm{fl}$ of SSB per day can increase the risk of having hypertension by at least $6 \%$, and it can increase MBP by a minimum of $1.8 \mathrm{mmHg}$ in roughly 18 months [42]. However, it remains unclear at what dose increased SSB intake leads to the development of hypertension. The suggestion is that an intake of $>1$ serving of SSB per day is associated with a higher risk of hypertension [42]. High-fructose corn syrup (HFCS) is the main source of added sweeteners in sweetened beverages. A high intake of HFCS causes an increase in BP and thus involves an increase in uric acid production which, in turn, results in a lowering of nitric oxide in the body $[43,44]$. Other hypotheses behind high SSB intake being implicated in hypertension involve decreased sodium excretion, activation of the sympathetic nervous system $[45,46]$, or an increased sodium concentration in the body through increased gut absorption [47]. Moreover, unhealthy lifestyle behaviors associated with increased sugar consumption by SSB go hand in hand with increased salt consumption leading to a higher BP $[48,49]$.

\subsubsection{Alcohol Consumption}

Alcohol consumption was associated with an increased BP in men. Notably, the strength of the association was distinct between both genders, and alcohol consumption did not reach significance in either gender and neither did alcohol consumption in women. In fact, high alcohol consumption and an increased BP and risk of hypertension have been described in several studies and in different populations [28,50]. Nevertheless, the relationship between hypertension and light-to-moderate alcohol consumption remains controversial in women [15]. A meta-analysis study assessed the presence of a gender-specific relationship between alcohol consumption and the risk of hypertension [14] and observed that high alcohol consumption was associated with the risk of hypertension in both genders, while moderate drinking was associated with a trend towards an increased risk of hypertension in men and a decreased risk in women. In our study, the difference in the magnitude of the effect among genders could be attributed to the differences in gender metabolism of drinking [51] and/or the patterns of drinking [52]. Accordingly, alcohol consumption should be limited in both genders [3].

Several studies have shown that ethanol consumption has a significant impact on blood pressure values, but this link remains complex [53]. Some mechanisms have been postulated for the hypertensive response to chronic ethanol consumption. Evidence suggests the existence of a myogenic mechanism involving alterations in the contractile and relaxant properties of vascular smooth muscle. Some studies have found that chronic ethanol consumption enhances the contractile response induced by phenylephrine in endothelium-intact aortic rings [54] and thus induces the contraction of blood vessels. Moreover, some studies have provided evidence that ethanol consumption alters plasma membrane permeability and then increases the intracellular $\mathrm{Ca}^{2+}$ concentration [53]. Importantly, 
ethanol consumption generates reactive oxygen species (ROS), which are a common mediator of remodeling and endothelial dysfunction [55]. Increased vascular oxidative stress induced by ethanol consumption is related to the activation of the enzyme nicotinamide adenine dinucleotide phosphatase $(\mathrm{NAD}(\mathrm{P}) \mathrm{H})$ oxidase, and this pathway is associated with the increased blood pressure cause by chronic ethanol consumption [53]. Some evidence implicates the sympathetic nervous system, the renin-angiotensin-aldosterone system, increased intracellular $\mathrm{Ca}^{2+}$ in vascular smooth muscle, oxidative stress, decreased NO bioavailability, and endothelial dysfunction as underlying mechanisms that increase BP in association with ethanol consumption, but this issue remains an open one [53].

It should be noted that, as expected, in a previous French cohort, wine was the primary type of alcohol consumed (66\% of alcohol consumption in both genders) [28]. However, in the Esteban survey, alcohol consumption was investigated in a global way without looking at the types of alcohol consumed. Alcohol consumption uniformly increases BP and CV risk events. Moderate alcohol intake could have a protective effect, but this link remains unclear [56].

\subsubsection{Strengths and Limitations}

The main strength of our study is that participants of the ESTEBAN survey are representative of the general French population. The data were collected using standardized protocols which add validity to our study's results.

However, some limitations are present in our study. The self-administered questionnaire on weight history may have been subject to memory biases which would alter patient answers about social difficulties, recent financial limitations, refraining from care, weight variation, and age at which this variation occurred. Medical history and comorbidities were collected from insurance database notifications, self-reporting and physician assertions during medical examination in health centers. They were less subject to misinterpretation and under or over-reporting. The cross-sectional design of the study may represent a limitation. In cross-sectional analyses, reverse causation cannot be excluded.

\section{Conclusions}

Approaches to the promotion of changes in lifestyle, including diet, are highly desirable to reduce $\mathrm{BP}$ levels and CV risk events or to avoid side effects related to chronic drug use. The DASH score, a general model of a health-conscious diet that is able to influence BP, could have implications in terms of public health and should be translated into dietary recommendations for the general population. Health professionals should continue to promote the consumption of vegetables and legumes due to the multiple effects of these food groups [57]. Red and processed meat consumption should be lowered. Even though no association has been observed between BP and alcohol consumption in women, health professionals should promote the lowering of excessive alcohol consumption level in both genders [58]. Moreover, recommendations based on dietary and drinking patterns may be a more comprehensive approach to the prevention of hypertension compared to single nutrition recommendations.

Author Contributions: A.V. performed the study design, analysis plan, statistical analyses and drafted the manuscript. A.V., J.B., and V.O. developed the research question. A.G., J.B., V.D. and V.O. contributed to the study design and analysis plan. A.G. and V.O. acquired the data. All authors critically revised the manuscript, gave final approval and agree to be accountable for all aspects of work ensuring integrity and accuracy.

Funding: This research received no external funding.

Acknowledgments: The authors thank the Centers for Health Examinations, the Cetaf and the laboratories involved in the collection, as well as the entire Esteban team and study participants. The Esteban study, from the National Biosafety launches, is financed by the Ministry of Solidarities and Health and the Ministry of Ecological and Solidarity Transition.

Conflicts of Interest: The authors declare no conflict of interest. 


\section{References}

1. Beaglehole, R.; Bonita, R.; Horton, R.; Adams, C.; Alleyne, G.; Asaria, P.; Baugh, V.; Bekedam, H.; Billo, N.; Casswell, S.; et al. Priority actions for the non-communicable disease crisis. Lancet 2011, 377, 1438-1447. [CrossRef]

2. WHO. A Global Brief on Hypertension. Available online: http://apps.who.int/iris/bitstream/10665/79059/1/ WHO_DCO_WHD_2013.2_eng.pdf (accessed on 4 April 2019).

3. Williams, B.; Mancia, G.; Spiering, W.; Rosei, E.A.; Azizi, M.; Burnier, M.; Clement, D.; Coca, A.; De Simone, G.; Dominiczak, A.; et al. 2018 Practice Guidelines for the management of arterial hypertension of the European Society of Hypertension and the European Society of Cardiology: ESH/ESC Task Force for the Management of Arterial Hypertension. J. Hypertens. 2018, 36, 2284-2309. [CrossRef] [PubMed]

4. Kawamura, A.; Kajiya, K.; Kishi, H.; Inagaki, J.; Mitarai, M.; Oda, H.; Umemoto, S.; Kobayashi, S. Effects of the DASH-JUMP dietary intervention in Japanese participants with high-normal blood pressure and stage 1 hypertension: An open-label single-arm trial. Hypertens. Res. 2016, 39, 777-785. [CrossRef] [PubMed]

5. Lelong, H.; Blacher, J.; Baudry, J.; Adriouch, S.; Galan, P.; Fezeu, L.; Hercberg, S.; Kesse-Guyot, E. Individual and Combined Effects of Dietary Factors on Risk of Incident Hypertension: Prospective Analysis from the NutriNet-Santé Cohort. Hypertension 2017, 70, 712-720. [CrossRef] [PubMed]

6. Lelong, H.; Blacher, J.; Menai, M.; Galan, P.; Fezeu, L.; Hercberg, S.; Kesse-Guyot, E. Association between Blood Pressure and Adherence to French Dietary Guidelines. Am. J. Hypertens. 2016, 29, 948-958. [CrossRef] [PubMed]

7. De Pergola, G.; D'Alessandro, A. Influence of Mediterranean Diet on Blood Pressure. Nutrients 2018, 10, 1700. [CrossRef] [PubMed]

8. Appel, L.J.; Champagne, C.M.; Harsha, D.W.; Cooper, L.S.; Obarzanek, E.; Elmer, P.J.; Stevens, V.J.; Vollmer, W.M.; Lin, P.-H.; Svetkey, L.P.; et al. Effects of comprehensive lifestyle modification on blood pressure control: Main results of the PREMIER clinical trial. JAMA 2003, 289, 2083-2093.

9. Blumenthal, J.A.; Babyak, M.A.; Hinderliter, A.; Watkins, L.L.; Craighead, L.; Lin, P.-H.; Caccia, C.; Johnson, J.; Waugh, R.; Sherwood, A. Effects of the DASH diet alone and in combination with exercise and weight loss on blood pressure and cardiovascular biomarkers in men and women with high blood pressure: The ENCORE study. Arch. Intern. Med. 2010, 170, 126-135. [CrossRef]

10. Appel, L.J.; Moore, T.J.; Obarzanek, E.; Vollmer, W.M.; Svetkey, L.P.; Sacks, F.M.; Bray, G.A.; Vogt, T.M.; Cutler, J.A.; Windhauser, M.M.; et al. A clinical trial of the effects of dietary patterns on blood pressure. DASH Collaborative Research Group. N. Engl. J. Med. 1997, 336, 1117-1124. [CrossRef]

11. Toledo, E.; de A Carmona-Torre, F.; Alonso, A.; Puchau, B.; Zulet, M.A.; Martinez, J.A.; Martinez-Gonzalez, M.A. Hypothesis-oriented food patterns and incidence of hypertension: 6-year follow-up of the SUN (Seguimiento Universidad de Navarra) prospective cohort. Public Health Nutr. 2010, 13, 338-349. [CrossRef]

12. Bendinelli, B.; Masala, G.; Bruno, R.M.; Caini, S.; Saieva, C.; Boninsegni, A.; Ungar, A.; Ghiadoni, L.; Palli, D. A priori dietary patterns and blood pressure in the EPIC Florence cohort: A cross-sectional study. Eur. J. Nutr. 2018, 58, 455-466. [CrossRef] [PubMed]

13. Saneei, P.; Salehi-Abargouei, A.; Esmaillzadeh, A.; Azadbakht, L. Influence of Dietary Approaches to Stop Hypertension (DASH) diet on blood pressure: A systematic review and meta-analysis on randomized controlled trials. Nutr. Metab. Cardiovasc. Dis. 2014, 24, 1253-1261. [CrossRef] [PubMed]

14. Briasoulis, A.; Agarwal, V.; Messerli, F.H. Alcohol consumption and the risk of hypertension in men and women: A systematic review and meta-analysis. J. Clin. Hypertens. 2012, 14, 792-798. [CrossRef] [PubMed]

15. Roerecke, M.; Tobe, S.W.; Kaczorowski, J.; Bacon, S.L.; Vafaei, A.; Hasan, O.S.M.; Krishnan, R.J.; Raifu, A.O.; Rehm, J. Sex-Specific Associations between Alcohol Consumption and Incidence of Hypertension: A Systematic Review and Meta-Analysis of Cohort Studies. J. Am. Heart Assoc. 2018, 7, e008202. [CrossRef] [PubMed]

16. Balicco, A.; Oleko, A.; Boschat, L.; Deschamps, V.; Saoudi, A.; Zeghnoun, A.; Fillol, C. Esteban design: A cross-sectional health survey about environment, biomonitoring, physical activity and nutrition (2014-2016). Toxicol. Anal. Clin. 2017, 29, 517-537. 
17. Fung, T.T.; Chiuve, S.E.; McCullough, M.L.; Rexrode, K.M.; Logroscino, G.; Hu, F.B. Adherence to a DASH-style diet and risk of coronary heart disease and stroke in women. Arch. Intern. Med. 2008, 168, 713-720. [CrossRef] [PubMed]

18. Ketteler, M.; Block, G.A.; Evenepoel, P.; Fukagawa, M.; Herzog, C.A.; McCann, L.; Moe, S.M.; Shroff, R.; Tonelli, M.A.; Toussaint, N.D.; et al. Diagnosis, Evaluation, Prevention, and Treatment of Chronic Kidney Disease-Mineral and Bone Disorder: Synopsis of the Kidney Disease: Improving Global Outcomes 2017 Clinical Practice Guideline Update. Ann. Intern. Med. 2018, 168, 422-430. [CrossRef] [PubMed]

19. Schneider, S. The International Standard Classification of Education 2011; Class and Stratification Analysis (Comparative Social Research); Birkelund, G.E., Ed.; Emerald Group Publishing Limited: Bingley, UK, 2013; Volume 30.

20. Ndanuko, R.N.; Tapsell, L.C.; Charlton, K.E.; Neale, E.P.; Batterham, M.J. Dietary Patterns and Blood Pressure in Adults: A Systematic Review and Meta-Analysis of Randomized Controlled Trials. Adv. Nutr. 2016, 7 , 76-89. [CrossRef]

21. Harrington, J.M.; Fitzgerald, A.P.; Kearney, P.M.; McCarthy, V.J.C.; Madden, J.; Browne, G.; Dolan, E.; Perry, I.J. DASH diet score and distribution of blood pressure in middle-aged men and women. Am. J. Hypertens. 2013, 26, 1311-1320. [CrossRef]

22. Dauchet, L.; Kesse-Guyot, E.; Czernichow, S.; Bertrais, S.; Estaquio, C.; Péneau, S.; Vergnaud, A.-C.; Chat-Yung, S.; Castetbon, K.; Deschamps, V.; et al. Dietary patterns and blood pressure change over 5-y follow-up in the SU.VI.MAX cohort. Am. J. Clin. Nutr. 2007, 85, 1650-1656. [CrossRef]

23. Schulze, M.B.; Hoffmann, K.; Kroke, A.; Boeing, H. Risk of hypertension among women in the EPIC-Potsdam Study: Comparison of relative risk estimates for exploratory and hypothesis-oriented dietary patterns. Am. J. Epidemiol. 2003, 158, 365-373. [CrossRef] [PubMed]

24. Borgi, L.; Curhan, G.C.; Willett, W.C.; Hu, F.B.; Satija, A.; Forman, J.P. Long-term intake of animal flesh and risk of developing hypertension in three prospective cohort studies. J. Hypertens. 2015, 33, 2231-2238. [CrossRef] [PubMed]

25. Miura, K.; Greenland, P.; Stamler, J.; Liu, K.; Daviglus, M.L.; Nakagawa, H. Relation of vegetable, fruit, and meat intake to 7-year blood pressure change in middle-aged men: The Chicago Western Electric Study. Am. J. Epidemiol. 2004, 159, 572-580. [CrossRef] [PubMed]

26. Ufnal, M.; Zadlo, A.; Ostaszewski, R. TMAO: A small molecule of great expectations. Nutrition 2015, 31, 1317-1323. [CrossRef] [PubMed]

27. Ufnal, M.; Jazwiec, R.; Dadlez, M.; Drapala, A.; Sikora, M.; Skrzypecki, J. Trimethylamine-N-oxide: A carnitine-derived metabolite that prolongs the hypertensive effect of angiotensin II in rats. Can. J. Cardiol. 2014, 30, 1700-1705. [CrossRef] [PubMed]

28. Lelong, H.; Galan, P.; Kesse-Guyot, E.; Fezeu, L.; Hercberg, S.; Blacher, J. Relationship between nutrition and blood pressure: A cross-sectional analysis from the NutriNet-Santé Study, a French web-based cohort study. Am. J. Hypertens. 2015, 28, 362-371. [CrossRef] [PubMed]

29. He, J.; Gu, D.; Chen, J.; Jaquish, C.E.; Rao, D.C.; Hixson, J.E.; Chen, J.; Duan, X.; Huang, J.; Chen, C.-S.; et al. Gender difference in blood pressure responses to dietary sodium intervention in the GenSalt study. J. Hypertens. 2009, 27, 48-54. [CrossRef]

30. Vernay, M.; Aïdara, M.; Salanave, B.; Deschamps, V.; Malon, A.; Oleko, A.; Mallion, J.-M.; Hercberg, S.; Castetbon, K. Diet and blood pressure in 18-74-year-old adults: The French Nutrition and Health Survey (ENNS, 2006-2007). J. Hypertens. 2012, 30, 1920-1927. [CrossRef]

31. Yang, Y.; Dong, B.; Zou, Z.; Wang, S.; Dong, Y.; Wang, Z.; Ma, J. Association between Vegetable Consumption and Blood Pressure, Stratified by BMI, among Chinese Adolescents Aged 13-17 Years: A National Cross-Sectional Study. Nutrients 2018, 10, 451. [CrossRef]

32. Whelton, P.K.; He, J.; Cutler, J.A.; Brancati, F.L.; Appel, L.J.; Follmann, D.; Klag, M.J. Effects of oral potassium on blood pressure. Meta-analysis of randomized controlled clinical trials. JAMA 1997, 277, 1624-1632. [CrossRef]

33. Whelton, S.P.; Hyre, A.D.; Pedersen, B.; Yi, Y.; Whelton, P.K.; He, J. Effect of dietary fiber intake on blood pressure: A meta-analysis of randomized, controlled clinical trials. J. Hypertens. 2005, 23, 475-481. [CrossRef] [PubMed] 
34. Sun, B.; Shi, X.; Wang, T.; Zhang, D. Exploration of the Association between Dietary Fiber Intake and Hypertension among U.S. Adults Using 2017 American College of Cardiology/American Heart Association Blood Pressure Guidelines: NHANES 2007-2014. Nutrients 2018, 10, 1091. [CrossRef] [PubMed]

35. Chiavaroli, L.; Viguiliouk, E.; Nishi, S.K.; Mejia, S.B.; Rahelić, D.; Kahleová, H.; Salas-Salvadó, J.; Kendall, C.W.; Sievenpiper, J.L. DASH Dietary Pattern and Cardiometabolic Outcomes: An Umbrella Review of Systematic Reviews and Meta-Analyses. Nutrients 2019, 11, 338. [CrossRef] [PubMed]

36. Coudray, C.; Demigné, C.; Rayssiguier, Y. Effects of dietary fibers on magnesium absorption in animals and humans. J. Nutr. 2003, 133, 1-4. [CrossRef] [PubMed]

37. Greger, J.L. Nondigestible carbohydrates and mineral bioavailability. J. Nutr. 1999, 129, 1434S-1435S. [CrossRef]

38. Beale, A.L.; Kaye, D.M.; Marques, F.Z. The role of the gut microbiome in sex differences in arterial pressure. Biol. Sex. Differ. 2019, 10, 22. [CrossRef]

39. Kim, S.; Goel, R.; Kumar, A.; Qi, Y.; Lobaton, G.; Hosaka, K.; Mohammed, M.; Handberg, E.M.; Richards, E.M.; Pepine, C.J.; et al. Imbalance of gut microbiome and intestinal epithelial barrier dysfunction in patients with high blood pressure. Clin. Sci. 2018, 132, 701-718. [CrossRef]

40. Marques, F.Z.; Nelson, E.; Chu, P.-Y.; Horlock, D.; Fiedler, A.; Ziemann, M.; Tan, J.K.; Kuruppu, S.; Rajapakse, N.W.; El-Osta, A.; et al. High-Fiber Diet and Acetate Supplementation Change the Gut Microbiota and Prevent the Development of Hypertension and Heart Failure in Hypertensive Mice. Circulation 2017, 135, 964-977. [CrossRef]

41. Pluznick, J.L.; Protzko, R.J.; Gevorgyan, H.; Peterlin, Z.; Sipos, A.; Han, J.; Brunet, I.; Wan, L.-X.; Rey, F.; Wang, T.; et al. Olfactory receptor responding to gut microbiota-derived signals plays a role in renin secretion and blood pressure regulation. Proc. Natl. Acad. Sci. USA 2013, 110, 4410-4415. [CrossRef]

42. Malik, A.H.; Akram, Y.; Shetty, S.; Malik, S.S.; Njike, V.Y. Impact of sugar-sweetened beverages on blood pressure. Am. J. Cardiol. 2014, 113, 1574-1580. [CrossRef]

43. Komnenov, D.; Levanovich, P.E.; Rossi, N.F. Hypertension Associated with Fructose and High Salt: Renal and Sympathetic Mechanisms. Nutrients 2019, 11, 569. [CrossRef] [PubMed]

44. Mas-Capdevila, A.; Iglesias-Carres, L.; Arola-Arnal, A.; Aragonès, G.; Aleixandre, A.; Bravo, F.I.; Muguerza, B. Evidence that Nitric Oxide is Involved in the Blood Pressure Lowering Effect of the Peptide AVFQHNCQE in Spontaneously Hypertensive Rats. Nutrients 2019, 11, 225. [CrossRef] [PubMed]

45. Brito, J.O.; Ponciano, K.; Figueroa, D.; Bernardes, N.; Sanches, I.C.; Irigoyen, M.C.; De Angelis, K. Parasympathetic dysfunction is associated with insulin resistance in fructose-fed female rats. Braz. J. Med. Biol. Res. 2008, 41, 804-808. [CrossRef] [PubMed]

46. Rebello, T.; Hodges, R.E.; Smith, J.L. Short-term effects of various sugars on antinatriuresis and blood pressure changes in normotensive young men. Am. J. Clin. Nutr. 1983, 38, 84-94. [CrossRef] [PubMed]

47. Singh, A.K.; Amlal, H.; Haas, P.J.; Dringenberg, U.; Fussell, S.; Barone, S.L.; Engelhardt, R.; Zuo, J.; Seidler, U.; Soleimani, M. Fructose-induced hypertension: Essential role of chloride and fructose absorbing transporters PAT1 and Glut5. Kidney Int. 2008, 74, 438-447. [CrossRef]

48. Feig, D.I.; Mazzali, M.; Kang, D.-H.; Nakagawa, T.; Price, K.; Kannelis, J.; Johnson, R.J. Serum uric acid: A risk factor and a target for treatment? J. Am. Soc. Nephrol. 2006, 17, S69-S73. [CrossRef]

49. He, F.J.; Marrero, N.M.; MacGregor, G.A. Salt intake is related to soft drink consumption in children and adolescents: A link to obesity? Hypertension 2008, 51, 629-634. [CrossRef]

50. Taylor, B.; Irving, H.M.; Baliunas, D.; Roerecke, M.; Patra, J.; Mohapatra, S.; Rehm, J. Alcohol and hypertension: Gender differences in dose-response relationships determined through systematic review and meta-analysis. Addiction 2009, 104, 1981-1990. [CrossRef]

51. Frezza, M.; di Padova, C.; Pozzato, G.; Terpin, M.; Baraona, E.; Lieber, C.S. High blood alcohol levels in women. The role of decreased gastric alcohol dehydrogenase activity and first-pass metabolism. N. Engl. J. Med. 1990, 322, 95-99. [CrossRef]

52. Seppä, K.; Laippala, P.; Sillanaukee, P. Drinking pattern and blood pressure. Am. J. Hypertens. 1994, 7, 249-254. [CrossRef]

53. Marchi, K.C.; Muniz, J.J.; Tirapelli, C.R. Hypertension and chronic ethanol consumption: What do we know after a century of study? World J. Cardiol. 2014, 6, 283-294. [CrossRef] 
54. Sahna, E.; Kurcer, Z.; Ozturk, F.; Cengiz, N.; Vardi, N.; Birincioglu, M.; Olmez, E. Effects of chronic ethanol consumption on alpha-adrenergic-induced contractions and endothelium-dependent relaxations in rat thoracic aorta. Pharmacol. Res. 2000, 41, 629-633. [CrossRef] [PubMed]

55. Takac, I.; Schröder, K.; Brandes, R.P. The Nox family of NADPH oxidases: Friend or foe of the vascular system? Curr. Hypertens. Rep. 2012, 14, 70-78. [CrossRef] [PubMed]

56. Millwood, I.Y.; Walters, R.G.; Mei, X.W.; Guo, Y.; Yang, L.; Bian, Z.; Bennett, D.A.; Chen, Y.; Dong, C.; $\mathrm{Hu}, \mathrm{R}$; ; et al. Conventional and genetic evidence on alcohol and vascular disease aetiology: A prospective study of 500,000 men and women in China. Lancet 2019, 393, 1831-1842. [CrossRef]

57. Van Duyn, M.A.; Pivonka, E. Overview of the health benefits of fruit and vegetable consumption for the dietetics professional: Selected literature. J. Am. Diet. Assoc. 2000, 100, 1511-1521. [CrossRef]

58. Roerecke, M.; Kaczorowski, J.; Tobe, S.W.; Gmel, G.; Hasan, O.S.M.; Rehm, J. The effect of a reduction in alcohol consumption on blood pressure: A systematic review and meta-analysis. Lancet Public Health 2017, 2 , e108-e120. [CrossRef]

(C) 2019 by the authors. Licensee MDPI, Basel, Switzerland. This article is an open access article distributed under the terms and conditions of the Creative Commons Attribution (CC BY) license (http://creativecommons.org/licenses/by/4.0/). 